\title{
Strawberry GenBank-derived and Genomic Simple Sequence Repeat (SSR) Markers and Their Utility with Strawberry, Blackberry, and Red and Black Raspberry
}

\author{
K.S. Lewers ${ }^{1,2}$, S.M.N. Styan ${ }^{3}$, and S.C. Hokanson ${ }^{4}$ \\ USDA-ARS Fruit Laboratory, 10300 Baltimore Avenue, BARC-West Building 010A, Beltsville, \\ MD 20705-2350 \\ N.V. Bassil ${ }^{2}$ \\ USDA-ARS NCGR, 33447 Peoria Road, Corvallis, OR 97333
}

ADDITIONAL INDEX WORDS. Fragaria, Fragaria $\times$ ananassa, Fragaria chiloensis, Fragaria iinumae, Fragaria vesca, Fragaria virginiana, Rubus, Rubus idaeus, Rubus occidentalis

\begin{abstract}
Although simple sequence repeat (SSR) markers have been developed for species in the closely related genera Fragaria L. (strawberry) and Rubus L. (raspberry and blackberry), the number of SSRs available is insufficient for genetic mapping. Our objective was to use and compare multiple approaches for developing additional SSRs for Fragaria and Rubus. The approaches included: the development of SSRs from GenBank sequences from species of varied relatedness to Fragaria and Rubus and identified with two different data-mining methods (BLAST and SSRIT); the evaluation of some previously published SSRs designed from related species; and the development of SSRs from a genomic library made from $F$. xananassa Duschene ex Rozier 'Earliglow'. When an SSR was developed from a known gene sequence, the location of the repeat in the gene was determined to evaluate the effect on amplification and polymorphism detection. Cross-generic amplification between closely related Fragaria and Rubus as well as transference from species of varied relatedness to Fragaria and Rubus also was evaluated and indicated limited transference within the subfamily Rosoideae. However, development of SSRs for Fragaria and Rubus from Rosa L. (rose) and Rosaceae genera outside Rosoideae was not efficient enough to be practical for new map development. SSRIT was superior to BLAST for identifying GenBank sequences containing repeats. SSRs developed from repeats found in either the $5^{\prime}$ UTR $\left(80 \%\right.$ polymorphic) or $3^{\prime}$ UTR $(85 \%$ polymorphic) were most likely to detect polymorphisms, compared with those developed from coding regions $(30 \%)$. SSRs developed from the genomic library were only slightly superior to GenBank-derived SSRs in their ability to detect polymorphisms.
\end{abstract}

Single sequence repeat (SSR) molecular markers have become valuable genetic markers in plant studies, with applications that include linkage mapping (Akkaya et al., 1995), cultivar identification (Rongwen et al., 1995), marker-assisted selection (Fazio et al., 2003), and gene flow characterization (Aldrich and Hamrick, 1998; Chase et al., 1996). SSRs are especially advantageous in genetic mapping research because they are easy to use, they map to similar locations in multiple populations (Cregan et al., 1999),

Received for publication 2 Mar. 2004. Accepted for publication 6 July 2004. We thank Isabella Mackey and Kate Rappaport for managing the PCR work and DNA extractions, and Peter Boches, Sony Thomas, and Michael Henry for helping with the DNA extractions and/or completing PCR amplifications. Thanks also to Sam Garrett for plant maintenance. We also thank Dr. Ben Matthews and Margaret McDonald for soybean and peach DNA, Dr. Tom Davis for DNA from parents of the $F$. vesca mapping population, and Sam Garrett, Dr. Courtney Weber, Dr. John Clark, and Eric Stafne for raspberry and blackberry leaf tissue. In addition, we would like to thank Dr. Tad Sonstegard and Tina Sphon for genotyping, and the Beltsville Agricultural Research Center for supporting the genotyping effort. Finally, we would like to thank Dr. Freddi Hammerschlag, Dr. Kim Hummer, Dr. Jeannie Rowland, Dr. Perry Cregan, Dr. Hilde Nybom, and the anonymous reviewers for helpful criticism of this work. Mention of trade names or commercial products is solely for the purpose of providing specific information and does not imply recommendation or endorsement by the U.S. Dept. of Agriculture.

'To whom reprint requests should be addressed. E-mail: lewersk@ba.ars.usda.gov ${ }^{2}$ To be considered co-first authors.

${ }^{3}$ Current address: Pioneer Hi-Bred International, Inc. A DuPont Co., Waimea Research Center, P.O. Box 609, Waimea, HI 96796.

${ }^{4}$ Current address: Dept. of Horticulture and Landscape Architecture, Univ. of Minnesota, St. Paul, MN 55108. and are associated with gene clusters, and potentially with traits, in plant genomes (Morgante et al., 2002). Some researchers have tried to reduce the time and expense of SSR development by using SSRs from one species for genetic research on related species (Cipriani et al., 1999; Cordeiro et al., 2001; Dayanandan et al., 1997; Decroocq et al., 2003; Dirlewanger et al., 2002; Downey and Iezzoni, 2000; Echt et al., 1999; Isagi and Suhandono, 1997; Peakall et al., 1998; Rajora et al., 2001; Scott et al., 2000; Steinkellner et al., 1997; Whitton et al., 1997). Other researchers designed primers from SSR-containing genomic and EST sequences archived in GenBank (Broun and Tanksley, 1996; Cho et al., 2000; da Silva, 2001; Holland et al., 2001; Kantety et al., 2002; Smulders et al., 1997).

Although SSR markers have been developed for species in the closely related genera Fragaria and Rubus, the number of SSRs available is insufficient for genetic mapping. Ten SSRs were developed for the diploid $F$. vesca L. (James et al., 2003); 22 were developed from the diploid $F$. viridis Weston (Sargent et al., 2003); four were developed for the paternal octoploid progenitor, F. virginiana Mill., of cultivated strawberry (Ashley et al., 2003); and four were developed from the cultivated octoploid strawberry $F$. xananassa (Ashley et al., 2003). Twenty-one SSRs developed from Prunus persica (L.) Batsch (peach) were reported to amplify products from $F$. xananassa DNA(Dirlewanger et al., 2002). Ten SSRs were developed from $R$. idaeus L. (red raspberry) (Graham et al., 2002) and eight SSRs were developed from $R$. alceifolius Poir. (Amsellem et al., 2001). Our objective was to use and 
compare multiple approaches for developing additional SSRs for Fragaria and Rubus. The approaches included the development of new SSRs from GenBank sequences from species of varied relatedness to Fragaria and Rubus and identified with two different data-mining methods (BLAST and SSRIT); the evaluation of some previously published SSRs designed from related species; and the development of new SSRs from a genomic library made from $F$. xananassa. When an SSR was developed from a known gene sequence, the location of the repeat in the gene was determined to evaluate the effect on amplification and polymorphism detection. Cross-generic amplification between closely related Fragaria and Rubus as well as transference from species of varied relatedness to Fragaria and Rubus also was evaluated.

\section{Materials and Methods}

Determining FUnCtional TAXoNOMIC DISTANCE FOR SSR DEVELOPMENT. An initial study was conducted to determine how taxonomically distant the source of the repeat sequence could be and still supply primers that would amplify a product from the two target species. We tested six $(\mathrm{CT})_{\mathrm{n}}$-containing primer pairs from each of nine genera with varied relatedness to Fragaria and Rubus. We searched GenBank using the National Center for Biotechnology Information's (NCBI) BLAST program (Altshul et al., 1990; National Center for Biotechnology Information, 2004) for genomic and EST sequences containing CT repeats in nine genera, using the sequence $(\mathrm{CT})_{30}$ as the query sequence. A total of 54 sequences containing $(\mathrm{CT})_{\mathrm{n}}$ repeats were selected for primer design. The taxonomically farthest genus from which primers were designed was within Rosideae, which includes the model species, Arabidopsis thaliana (L.) Hehnh; six repeat-containing A. thaliana sequences were selected for primer design. From the next taxonomic level closer to Fragaria and Rubus, the eurosids I, 12 primers were designed from the Fabaceae Lindl., nom. cons. family [six from Glycine max (L.) Merr. (soybean); and six from Medicago truncatula Gaertn. (a model legume)], and six from the Malvaceae family [Gossypium L. (cotton)]. Within the Rosaceae family, six primer pairs were designed from Prunus persica representing the subfamily Prunoideae, and 12 primer pairs were designed from species representing the subfamily Maloideae (six from Pyrus communis L. and six from Malus $\times$ domestica Borkh). In the subfamily Rosoideae, to which the two target genera, Fragaria and Rubus, belong, six primer pairs were obtained from $F$. ×ananassa and six from Rosa (rose). Primers were developed with the on-line version of Primer3 software (Whitehead Institute for Biomedical Research, 2004) using the default settings (Rozen and Skaletsky, 2000). The recommended primers were synthesized without modification by Operon Technologies (Qiagen, Valencia, Calif.). In addition, several published SSR primers were tested and included 21 primer pairs designed from Prunus persica and reported to amplify a product from strawberry (Dirlewanger et al., 2002); eight primer pairs developed from Rubus alceifolius (Amsellem et al., 2001); four SSR primer pairs designed from $F$. virginiana genomic sequences (Ashley et al., 2003); and 10 designed from $F$. vesca (diploid) genomic sequences (James et al., 2003).

DEVELOPMENT OF ADDITIONAL SSRS FROM F RAGARIA SEQUENCES IN GenBank. Two methods were used to identify GenBank Fragaria sequences containing repeats. The first was the direct BLAST search method used above with (CT)-containing SSRs to determine the taxonomic distance for SSR transference to Fragaria and Rubus. Genomic and EST sequences of Fragaria
GenBank sequences were searched using all possible (dinucleotide) ${ }_{30}$ and (trinucleotide) ${ }_{20}$ repeats as a query sequence. The second method of finding GenBank sequences containing repeats used the Perl script SSRIT (simple sequence repeat identification tool) (Gramene, 2004; Temnykh et al., 2001). A total of 306 genomic and EST Fragaria sequences present in the nucleotide database of the NCBI were screened for repeat sequences. The maximum motif length group selected was pentamer, and the minimum number of tandem repeats was set at five (and then also later at four to identify additional repeat-containing sequences).

The location of the simple sequence repeat in the gene was determined to evaluate the effect on amplification and polymorphism detection. If available, the genomic as well as the coding sequence of the repeat-containing GenBank sequences were aligned using the CLUSTALW algorithm (Institute for Chemical Research, 2000; Thompson et al., 1994), enabling the identification of the repeat location with respect to the gene. Alternatively, the repeat-containing sequence was compared against known gene sequences archived in GenBank using the BLASTN algorithm. For each sequence, the location of the repeat region [ $5^{\prime}$ untranslated region (5'UTR), intron, exon, or $3^{\prime}$ untranslated region (3'UTR)] was determined. Whenever possible, primers were designed in the coding regions of the gene. After eliminating duplicated sequences and sequences that contained repeats at their ends, primer pairs were designed from 25 sequences using Primer3 (Table 1).

SSR DEVELOPMENT FROM A GENOMIC LIBRARY. Fragaria $\times$ ananassa 'Earliglow' genomic DNA was digested with restriction enzymes Sma I, Msc I, and Rsa I. The resulting DNA fragments were phosphorylated and electrophoretically separated through a $0.8 \%$ agarose, $1 \times$ TBE gel. The DNA fragments between $400-800$ base pairs (bp) were extracted and purified from the gel according to the QIAquick Gel Extraction Kit protocol (Qiagen). Purified DNA fragments were ligated into the Sma I site of the pUC 19 vector with T4 ligase (New England BioLabs, Beverly, Mass.), and transformed into Epicurian Coli Ultracompetent Cells (Stratagene, La Jolla, Calif.). Transformed cells were grown on LB-agar plates containing $50 \mathrm{mg} \cdot \mathrm{mL}^{-1}$ of ampicillin, $40 \mathrm{mg} \cdot \mathrm{mL}^{-1}$ of X-gal (5bromo-4chloro-3indolyl- $\beta$-D-galactopyranoside), and $40 \mathrm{mg} \cdot \mathrm{mL}^{-1}$ IPTG (isopropyl-1-thio- $\beta$-D-galactopyranoside). White colonies were transferred to Optitran BA-S85 membranes (Schleicher \& Schuell, Keene, N.H.), and hybridized with ${ }^{32} \mathrm{P}$-labeled (CT) probe. After three rounds of screening, single bacterial colonies were grown and selected for plasmid DNA isolation using the QIAprep Miniprep Kit (Qiagen).

Plasmid DNA from the selected positive clones was diluted to $100 \mathrm{ng} \cdot \mu \mathrm{L}^{-1}$ for sequencing reactions. Clone inserts were sequenced from both ends using M13 17-mer forward and 24-mer reverse sequencing primers (New England Biolabs) in the BigDye Terminator Cycle sequence ready reaction mixture (Applied Biosystems, Foster City, Calif.) according to the supplied protocol. The reaction products were analyzed with an ABI 310 Automated DNA Sequencer (Applied Biosystems). Repeat-containing sequences were compared against known gene sequences contained in GenBank using the BLASTN and BLASTX algorithms.

Oligo Lite, Version 6 (Molecular Biology Insights, Cascade, Colo.) was used for primer design. Primers were chosen under the highest stringency conditions possible with criterion including primer efficiency (PE) values $>400$, duplex values $>-4$, and a melting temperature difference of $\leq 20{ }^{\circ} \mathrm{C}$ between primer pairs. Twenty-eight primer pairs were synthesized by BioServe Biotechnologies, Ltd. (Laurel, Md.) (Table 1). 
GENOTYPES USED FOR PRIMER TESTING IN F RAGARIA AND $\boldsymbol{R} U$ bUS. SSR primers were tested in PCR amplification with genomic DNA from 31 genotypes (Table 2): 12 F. xananassa (octoploid) genotypes (cultivated octoploid strawberry), five F. chiloensis (L.) Mill. genotypes (octoploid maternal progenitor species of cultivated strawberry), three $F$. virginiana genotypes (octoploid paternal progenitor species of cultivated strawberry), one $F$. virginiana $\times F$. $\times$ ananassa hybrid (octoploid), four $F$. vesca (diploid) genotypes, one $F$. iinumae Makino (diploid), and six Rubus genotypes (four tetraploid blackberry, one diploid red raspberry, and one diploid black raspberry). Many of these genotypes are parents of existing mapping populations and were selected so that we could obtain polymorphism data for multiple mapping populations (Tables 2 and 3). Plants were grown at multiple locations: the USDA-ARS National Clonal Germplasm Repository at Corvallis, Ore.; the USDA-ARS Beltsville Agricultural Research facility at Beltsville, Md.; the Univ. of Arkansas station near Clarksville, Ark.; and Cornell Univ. near Geneva, N.Y. Not all of the primers were tested on every genotype.

DNAEXTRACTION. DNA was obtained from plants by harvesting young leaves from greenhouse- or field-grown plants. At Corvallis,
DNA was extracted from four leaf discs using the PureGene kit (Gentra Systems, Minneapolis) according to the recommended plant protocol. DNA concentrations were estimated spectrophotometrically using a Biophotometer (Brinkmann Instruments, Westbury, N.Y.) and diluted to $2.5 \mathrm{ng} \cdot \mu \mathrm{L}^{-1}$ with $1 \times \mathrm{TE}$ buffer. At Beltsville, DNA was extracted using Qiagen's DNeasy Plant Maxi Kit or DNeasy Plant Mini Kit. DNA was quantified using the Spectramax 190 spectrophotometer (Molecular Devices, Sunnyvale, Calif.), and diluted with $1 \times \mathrm{TE}$ buffer to $30 \mathrm{ng} \cdot \mu \mathrm{L}^{-1}$. Dilutions to $0.03 \mathrm{ng} \cdot \mu \mathrm{L}^{-1}$ were made with $\mathrm{ddH}_{2} \mathrm{O}$.

PCR CONDitions. At Corvallis, PCR amplifications were carried out in $10 \mu \mathrm{L}$ total volume of $1 \times$ Biolase reaction buffer, 2 $\mathrm{mm} \mathrm{MgCl}_{2}, 0.2 \mathrm{~mm}$ each of dATP, dCTP, dGTP, and dTTP, 0.3 $\mu \mathrm{M}$ each of forward and reverse primers, $0.25 \mathrm{U}$ of Biolase Taq DNA polymerase (Bioline USA, Randolph, Mass.), and $2.5 \mathrm{ng}$ of template DNA. DNA was amplified for 35 cycles in an Eppendorf Gradient thermocycler (Brinkmann Instruments, Westbury, N.Y.) or an MJ Research Tetrad thermocycler (MJ Research, Waltham, Mass.) programmed for a 40 -s denaturation step at $94{ }^{\circ} \mathrm{C}$, a $40-\mathrm{s}$ annealing step at the optimum annealing temperature, and a 40s extension step at $72^{\circ} \mathrm{C}$. The optimum annealing temperature

Table 1. Primer pairs tested in polymerase chain reactions (PCRs) with template DNA from several Fragaria and Rubus genotypes. The primer pairs were either published previously or developed from nucleotide sequences containing simple sequence repeats (SSRs). The SSR-containing sequences were identified from among Fragaria or Rubus sequences archived in the GenBank database or from a genomic library made from $F$. xananassa 'Earliglow' DNA. The source sequence GenBank accession number, clone number, and/or reference (if published) for each primer pair are given. Location of the SSR with respect to the gene is indicated when known. If a primer pair amplified a product in PCR reactions with any tested genotype in the listed species, a "+" sign is indicated. If the primer pair also detected polymorphisms among the tested genotypes in the listed species, a "+/+" sign is indicated. If the primer pair did not amplify a product from any of the genotypes tested in the listed species, a "-" sign is indicated. If the primer pair was not tested on any of the genotypes in the species, no sign is given.

\begin{tabular}{|c|c|c|c|c|c|c|c|c|c|c|c|c|c|}
\hline Marker ${ }^{2}$ & $\begin{array}{l}\text { GenBank or } \\
\text { library accession, } \\
\text { source genome, } \\
\text { sequence } \\
\text { similarity } \mathrm{y}, \mathrm{x}\end{array}$ & $\begin{array}{l}\text { Primer sequences } 5^{\prime} \text { to } 3^{\prime} \text {, or } \\
\text { source reference if published }\end{array}$ & $\begin{array}{l}\mathrm{Tm} \\
{ }^{\circ} \mathrm{C}\end{array}$ & $\begin{array}{l}\text { Size } \\
(b p)^{\mathrm{w}}\end{array}$ & Repeat $^{v}$ & Location & 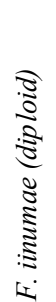 & 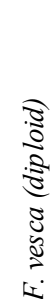 & 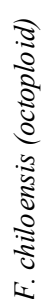 & 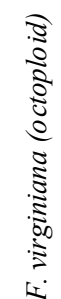 & 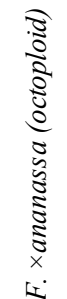 & 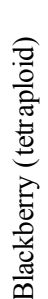 & 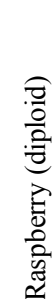 \\
\hline Fvi6b & $\begin{array}{l}\text { None, } F \text {. } \\
\text { virginiana, NA }\end{array}$ & Ashley et al., 2003 & 56 & 282 & $(\mathrm{ga})_{15}$ & NP & & - & + & $+/+$ & $+/+$ & & - \\
\hline Fvi9 & $\begin{array}{l}\text { None, } F \text {. } \\
\text { virginiana, NA }\end{array}$ & Ashley et al., 2003 & 60 & 175 & $(\mathrm{ca})_{11}$ & NP & & + & + & $+/+$ & $+/+$ & & - \\
\hline Fvil1 & $\begin{array}{l}\text { None, } F \text {. } \\
\text { virginiana, NA }\end{array}$ & Ashley et al., 2003 & 60 & 137 & $(\mathrm{ga})_{16}$ & NP & & + & + & $+/+$ & $+/+$ & & - \\
\hline EMFv2 & $\begin{array}{l}\text { AJ508245, } F \\
\text { vesca, NA }\end{array}$ & James et al., 2003 & 60 & 278 & $(\operatorname{agc})_{10}$ & NP & & + & + & + & + & - & - \\
\hline EMFv3 & $\begin{array}{l}\text { AJ508246, } F \\
\text { vesca, } \mathrm{NA}\end{array}$ & James et al., 2003 & 50 & 241 & $(\mathrm{ag})_{22-1}$ & NP & & $+/+$ & + & + & $+/+$ & - & - \\
\hline EMFv4 & $\begin{array}{l}\text { AJ508247, } F \\
\text { vesca, NA }\end{array}$ & James et al., 2003 & 50 & 277 & $(\mathrm{ag})_{15}$ & NP & & $+/+$ & + & + & $+/+$ & - & $+/+$ \\
\hline EMFv5 & $\begin{array}{l}\text { AJ508248, } F \\
\text { vesca, NA }\end{array}$ & James et al., 2003 & 60 & 194 & $(\operatorname{cgg})_{7}$ & NP & & + & + & + & $+/+$ & - & - \\
\hline EMFv6 & $\begin{array}{l}\text { AJ508249, } F \\
\text { vesca, NA }\end{array}$ & James et al., 2003 & 60 & 228 & $(\mathrm{ag})_{31}$ & NP & & $+/+$ & + & + & $+/+$ & - & - \\
\hline
\end{tabular}

Table 1 continued next page 
GenBank or

library accession, source genome, sequence
similarity ${ }^{y, x}$

Primer sequences 5' to 3', or Tm Size

Marker $^{\mathrm{z}}$ source reference if published

${ }^{\circ} \mathrm{C} \quad(\mathrm{bp})^{\mathrm{w}}$ Repeat $^{\mathrm{v}}$

Location

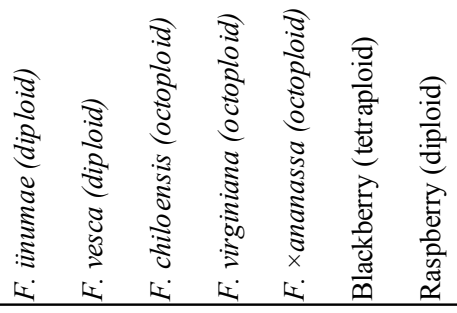

\begin{tabular}{|c|c|c|c|c|c|c|c|c|c|c|c|c|c|}
\hline \multicolumn{2}{|c|}{ Previously published SSRs } & \multirow[b]{2}{*}{ James et al., 2003} & \multirow[b]{2}{*}{60} & \multirow[b]{2}{*}{214} & \multirow[b]{2}{*}{$(\mathrm{ag})_{22}$} & \multirow[b]{2}{*}{ NP } & & \multirow[b]{2}{*}{$+/+$} & \multirow[b]{2}{*}{+} & \multirow[b]{2}{*}{+} & \multirow[b]{2}{*}{$+/+$} & \multirow[b]{2}{*}{-} & \multirow[b]{2}{*}{-} \\
\hline EMFv7 & $\begin{array}{l}\text { AJ508250, } F \\
\text { vesca, NA }\end{array}$ & & & & & & & & & & & & \\
\hline EMFv8 & $\begin{array}{l}\text { AJ508251, } F \\
\text { vesca, NA }\end{array}$ & James et al., 2003 & 60 & 206 & $(\mathrm{ag})_{18}$ & NP & & $+/+$ & + & + & $+/+$ & & - \\
\hline EMFv9 & $\begin{array}{l}\text { AJ508252, } F \\
\text { vesca, NA }\end{array}$ & James et al., 2003 & 60 & 206 & $(\mathrm{agc})_{8}$ & NP & & + & + & + & $+/+$ & + & $+/+$ \\
\hline EMFv10 & $\begin{array}{l}\text { AJ508253, } F \\
\text { vesca, NA }\end{array}$ & James et al., 2003 & 55 & 243 & $(\operatorname{cgg})_{7}$ & NP & & $+/+$ & + & + & + & - & - \\
\hline mRaCIRRI1G3 & $\begin{array}{l}\text { AF205116, } \\
\text { Rubus alceifolius, } \\
\text { NA }\end{array}$ & Amsellem et al., 2001 & 58 & $\begin{array}{l}195- \\
265\end{array}$ & $(\mathrm{ga})_{28}$ & NP & & + & + & + & - & + & $+/+$ \\
\hline mRaCIRRIV2A8 & $\begin{array}{l}\text { AF261693, } R \text {. } \\
\text { alceifolius, NA }\end{array}$ & Amsellem et al., 2001 & 59 & $\begin{array}{l}191- \\
237\end{array}$ & $(\mathrm{ca})_{12}(\mathrm{ct})_{11}$ & NP & & $+/+$ & + & + & - & $+/+$ & $+/+$ \\
\hline \multicolumn{2}{|c|}{ Derived from GenBank sequences } & & & & & & & & & & & & \\
\hline FAC-013 & $\begin{array}{l}\text { AF041394, } F \\
\times \text { ananassa, } \\
\text { FANR40, cDNA }\end{array}$ & $\begin{array}{l}\text { F:tgtttgaaaagtgct ggac } \\
\text { R:gatatcaatatcaatactagataacag }\end{array}$ & 58 & 192 & $(\text { aag })_{10}$ & & - & $+/+$ & $+/+$ & $+/+$ & $+/+$ & & \\
\hline ARSFL_97 & $\begin{array}{l}\text { AF041401, } \\
\text { 'Brighton', UDP } \\
\text { glu cose glucosyl- } \\
\text { transferase }\end{array}$ & $\begin{array}{l}\text { F:caagcaatccaacagctcaa } \\
\text { R:acgc ctctaagcacttcctg }\end{array}$ & 59 & 185 & $(\mathrm{ca})_{5}$ & Coding & & $+/+$ & + & + & $+/+$ & + & - \\
\hline ARSFL_34 & $\begin{array}{l}\text { AF041403, } \\
\text { 'Brighton', } \\
\text { flavonoid-3- } \\
\text { hydroxy lase(4) }\end{array}$ & $\begin{array}{l}\text { F:tctcaacgatcccaaaggag } \\
\text { R:ccaaatctccctcaccttga }\end{array}$ & 59 & 155 & $(\mathrm{ag})_{10-3}$ & Coding & & + & + & + & + & - & - \\
\hline ARSFL_35 & $\begin{array}{l}\text { AF054615, } \\
\text { 'Selva', cellulase } \\
\text { (Cel2) mRNA }\end{array}$ & $\begin{array}{l}\text { F:tgggatctgcttaggctttt } \\
\text { R:aage cactttttaccetcaa }\end{array}$ & 59 & 206 & $(\mathrm{ag})_{8}$ & 3'UTR & & + & $+/+$ & + & $+/+$ & - & - \\
\hline ARSFL_134 & $\begin{array}{l}\text { AF158652, } F \text {. } \\
\times \text { ananassa, } \\
\text { cytosolic } \\
\text { ascorbate } \\
\text { peroxidase } \\
\text { (ApxSC) }\end{array}$ & $\begin{array}{l}\text { F:ttct ttatggttgtgect gtct } \\
\text { R:ctccatccgctt gatecta }\end{array}$ & 59 & 184 & $(\operatorname{tgg})_{2}(\operatorname{ttg})_{4}$ & Intron2 & & + & + & + & + & + & + \\
\hline ARSFL_99 & $\begin{array}{l}\text { AF } 159563 \text {, } \\
\text { 'Chandler', } \\
\text { expansin au xin- } \\
\text { independent }\end{array}$ & $\begin{array}{l}\text { F:gattagggagaggcaac gt g } \\
\text { R:gcttcaagcaaaatgcatca }\end{array}$ & 59 & 178 & (at $)_{13-1}$ & 3'UTR & & $+/+$ & + & + & $+/+$ & - & - \\
\hline FAC-011 & $\begin{array}{l}\text { AF159563, } \\
\text { 'Chandler', } \\
\text { expansin au xin- } \\
\text { independent }\end{array}$ & $\begin{array}{l}\text { F:gttttcaggcggtcaattcta } \\
\text { R:gcttcaagcaaaatgcatcatc }\end{array}$ & 64 & 298 & $(\mathrm{ta})_{7} \mathrm{a}(\mathrm{at})_{6}$ & 3'UTR & + & $+/+$ & + & $+/+$ & $+/+$ & & \\
\hline FAC-010 & $\begin{array}{l}\text { AF220491, } F \text {. } \\
\times \text { ananassa, } \mathrm{O}- \\
\text { methyltransferase } \\
(\text { omt } 1)\end{array}$ & $\begin{array}{l}\text { F:gct gtgat gctttcaacaccta } \\
\text { R:ttgctgcacccatacttagaaa }\end{array}$ & 48 & 278 & $(\mathrm{ctt})_{5}$ & 3'UTR & - & - & - & - & - & & \\
\hline
\end{tabular}




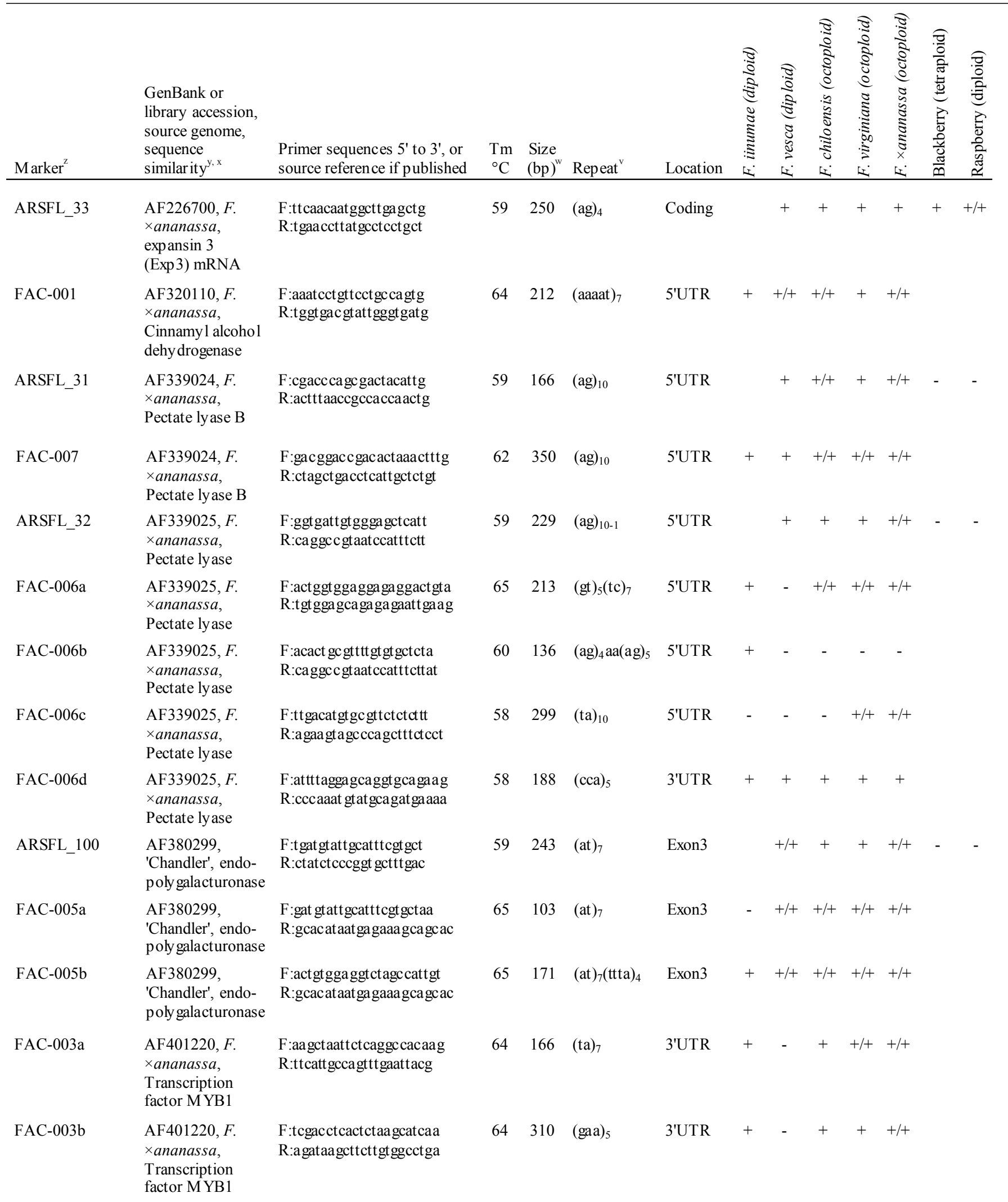


GenBank or

library accession, source genome,

\begin{tabular}{|c|c|}
\hline Marker ${ }^{2}$ & $\begin{array}{l}\text { sequence } \\
\text { similarity }^{y, x}\end{array}$ \\
\hline FAC-008 & $\begin{array}{l}\text { AF421492, } F \\
\times \text { ananassa, } \\
\text { Gly ceraldehyde } \\
\text { 3-phosphate } \\
\text { dehydrogenase } 1\end{array}$ \\
\hline
\end{tabular}

Primer sequences 5' to 3', or Tm Size source reference if published $\quad{ }^{\circ} \mathrm{C} \quad(\mathrm{bp})^{\mathrm{w}}$ Repeat ${ }^{\mathrm{N}}$

F:tactgtgcacgcaacaacag R:ctctccaatccttcattgat

$50 \quad 138$

$(\mathrm{tc})_{5} \mathrm{a}(\mathrm{tc})_{4}$ Location

$\begin{array}{ll}\text { ARSFL_98 } & \text { AI795160, } \\ & \text { 'Elsanta', } \\ & \text { Metallothionein- } \\ & \text { like protein }\end{array}$

FAC-009

AI795160,

'Elsanta',

Metallothioneinlike protein

ARSFL_105

AJ001448, $F$. vesca, 'Reine des Valles', ripeninginduced protein, clone 2.5.R1

FAC-014

AJ001448, $F$. vesca, 'Reine des Valles', ripeninginduced protein, clone 2.5.R1

ARSFL_101

AJ001451, $F$. vesca, 'Reine des Valles', putative cystathionine gamma synthase

ARSFL_107

AJ001451, $F$. vesca, 'Reine des Valles', putative cystathionine gamma synthase

AJ006349,

'Chandler', faEG3 gene for endo-

beta-1,4-

glucanase

FAC-002

AJ006349,

'Chandler', faEG3 gene for endo-

beta-1,4-

glu canase

ARSFL_106
'Chandler', lpt46 gene for lipid transfer protein
F:cccetattcgacaaccaatg

R:tggctaccaaagaacacgaa

F:catcgactgcaagt gtggac

R:tggctaccaaagaacacgaa

F:cagctccagctcgtcaagt

R:gacctcagt gtcctgetcgt

$59 \quad 295 \quad(\text { gaa })_{7-1}$

F:gactgaaggagaagctcaagga

R:gacctcagt gtcctgctcgtag

F:cagctaaaaccetgctctcg

R:gt gacgataggccgtgaaac

F:tccaacaaagactccgacct

R:gtccttcaaatcaggcaagc

$\begin{array}{lll}59 & 217 \quad(\mathrm{ac})_{6}\end{array}$

$\begin{array}{lll}64 & 244 & (\operatorname{tg})_{6}\end{array}$

F:ttcgaagattggagaagaaagg

R:aagc cactttttaccectcaa

F:tcatcctctttcacctccactt

$\mathrm{R}:$ tcaaaagacttggaaatgttgc

$64 \quad 236$

F:ttcatttcctatgtcggagaaa $\mathrm{R}: \mathrm{tttgttgatgaaaatgccaca}$ $\begin{array}{lll}62 & 224 \quad(\mathrm{gaa})_{7-1}\end{array}$

$\begin{array}{lll}59 & 218 \quad(\mathrm{agg})_{6}\end{array}$

Exon1

$59 \quad 183 \quad(\mathrm{ggc})_{6-1}$

Exon1

$\begin{array}{lll}59 & 161 \quad(\mathrm{ag})_{12}\end{array}$

3'UTR

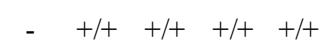


GenBank or

library accession, source genome,

Marker $^{\mathrm{z}}$ sequence

Primer sequences $5^{\prime}$ to $3^{\prime}$, or Tm Size similarity $\mathrm{y}, \mathrm{x}$ source reference if published

${ }^{\circ} \mathrm{C} \quad(\mathrm{bp})^{\mathrm{w}}$ Repeat

Location

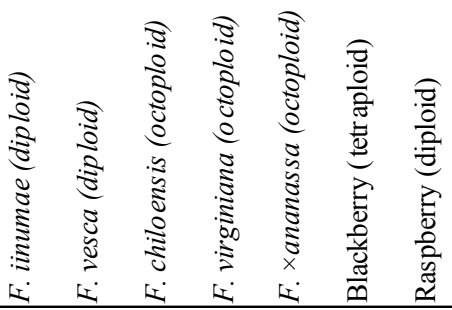

FAC-004a

AJ315844,

F:atgggagat gctcttagtggaa

$\begin{array}{lll}48 & 230 & (\operatorname{tg})_{6}\end{array}$

5'UTR $\quad+\quad-\quad+/+\quad+/+\quad+/+$

'Chandler', lpt46

R:acagattcggttcgtttattga

gene for lipid

transfer protein

FAC-004b

AJ315844,

'Chandler', lpt46

gene for lipid

transfer protein

FAC-004c

AJ315844,

'Chandler', lpt46

gene for lipid

transfer protein

FAC-004d

AJ315844,

'Chandler', lpt46

gene for lipid

transfer protein

FAC-016

AX025481, $F$.

$\times$ ananassa, 3 -

ketoacyl-CoA

thiolase

ARSFL_133

AY158836, $F$

$\times$ ananassa,

quinone

oxidoreductase

(QR) gene

FAC-012

FVY17185, $F$.

vesca 'Reine des

Valles', putative

cystathionine

gamma synthase

ARSFL_103

FXU19944,

'Pajaro', clone

RJ39 unknown

protein

ARSFL_104

FXU63631,

'Chandler', LMW

heat shock

protein

FAC-015a

X91839, $F$.

$\times$ ananassa, auxin-binding

protein

FAC-015b
F:atcaataaacgaaccgaatctg

R:gtcct gaaggt gga gaaatcag

F:gtccatactttaagc cgaat gc

R:acgtccettcacaataaaat gg

F:gecaat gttcgatgtttcacta

R:tccttgggtc gatcacataaat

$\mathrm{F}: t$ ttcaaga caggagcaagatca

R:agtggtggtcc catctttctta

F:aaact tgattggeggagaga

R:ttctgttttgaggcccagac

F:tacacgtgtcctagggttttca

$\mathrm{R}$ :agcggagaatgagtgacgatag

F:ggcagttgatgcttatgatga

R:attggatcttcaggcacacc

F:ctcgaatcgactggaaggag

R:gaacctcctcacgaacttgc

F:gaatttggac cgttgatttgat

$\mathrm{R}$ :attgcagagaagaaaagcaagc

F:gaacacgaggatttacaagtgc

R:aggtggttccagttcaagacat $\begin{array}{lll}48 & 254 & (\mathrm{ta})_{6}\end{array}$

$\begin{array}{lll}48 & 334 & (\mathrm{ta})_{8}(\operatorname{tg})_{5}\end{array}$

$\begin{array}{lll}58 & 350 & (\mathrm{gaa})_{6}\end{array}$

$\begin{array}{lll}64 & 233 \quad(\mathrm{gct})_{6}\end{array}$

$59 \quad 203 \quad(\text { gaa })_{3}$

5'UTR

$\begin{array}{lll}62 & 169 & (\mathrm{cct})_{6}\end{array}$

$59 \quad 171 \quad(\text { agg })_{9-4}$

Coding

$59 \quad 200 \quad(\operatorname{agg})_{4-1}$

Coding

$60 \quad 161 \quad(\mathrm{ctt})_{5}$

$64 \quad 292 \quad(t t t a)_{3}$

auxin-binding

protein 
GenBank or

library accession, source genome,

Marker

sequence

Primer sequences $5^{\prime}$ to $3^{\prime}$, or $\mathrm{Tm}$ Size similarity $^{\mathrm{y}, \mathrm{x}}$

source reference if published $\quad{ }^{\circ} \mathrm{C} \quad(b p)^{\mathrm{w}}$ Repeat $^{\mathrm{v}}$

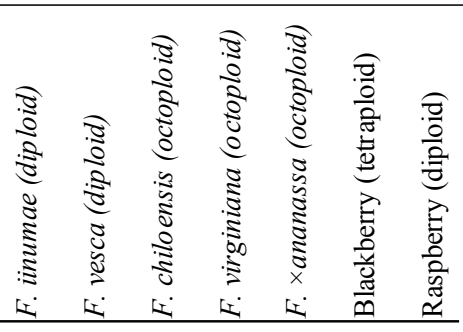

Derived from a genomic library

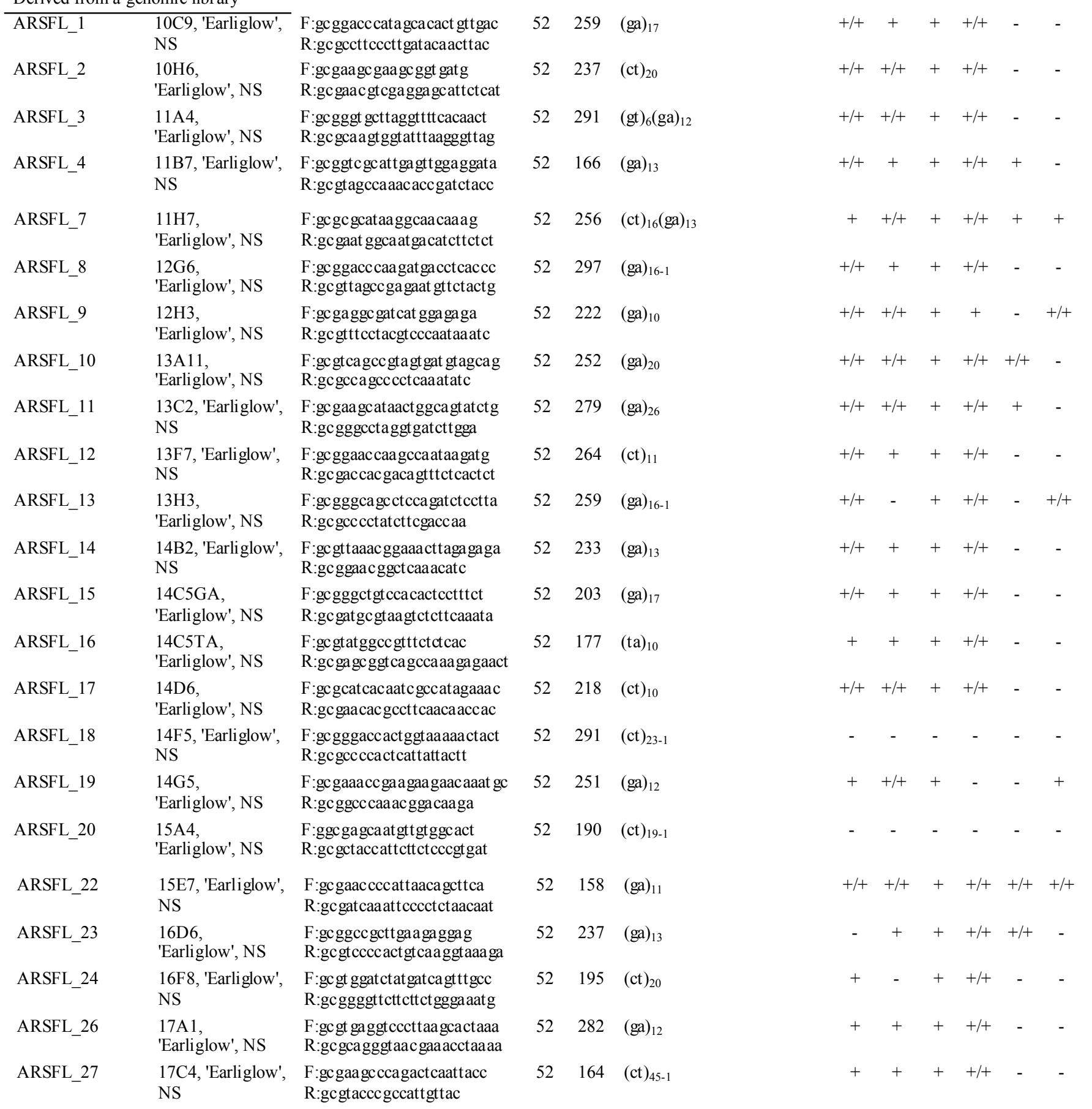




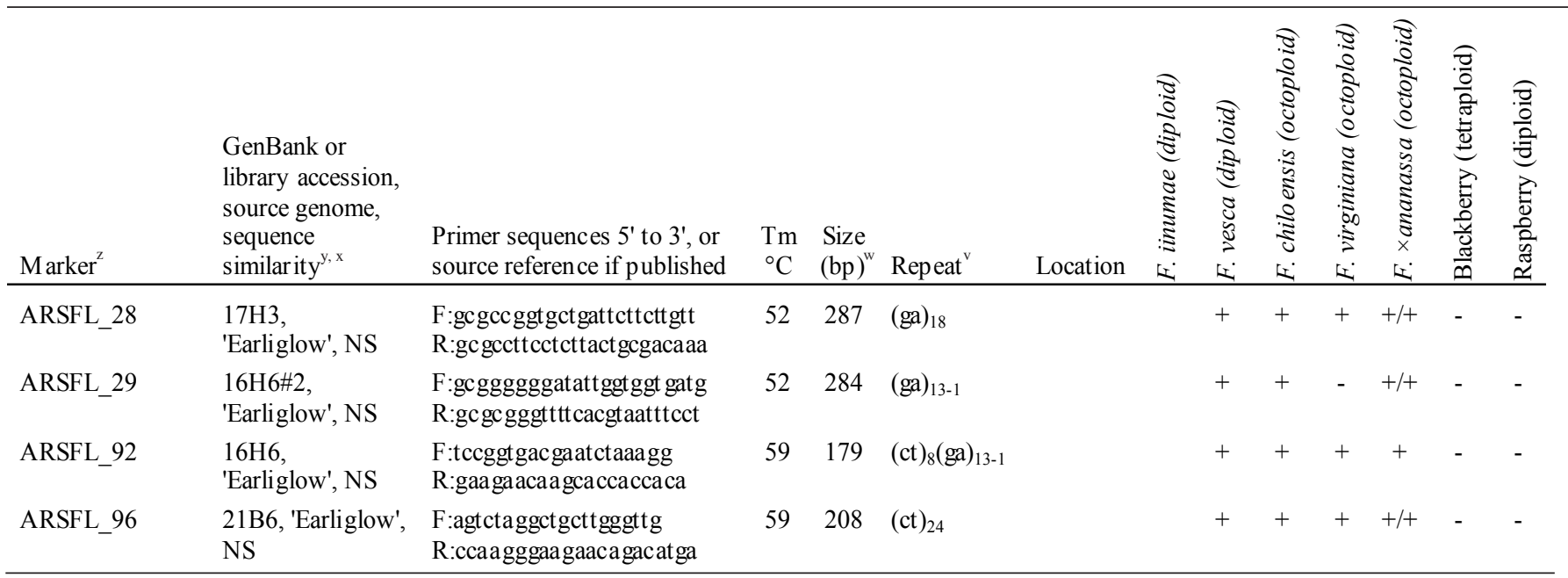

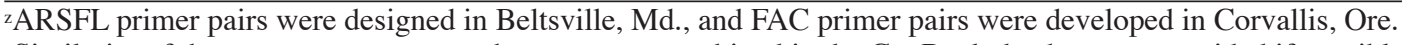

ySimilarity of the source sequence to other sequences archived in the GenBank database are provided if possible; if the similarity is not available, "NA" is indicated, and, if no similarity was found, "NS" is indicated.

${ }^{x}$ Sometimes the cultivar name was provided for $F$. xananassa-derived sequences; if a cultivar name is provided, it is $F$. $\times a n a n a s s a$ unless otherwise stated.

wThe expected PCR product size in base pairs (bp) is based on the sequence from which each primer pair is derived.

vThe simple sequence motifs identified in the source sequences are indicated as the simple sequence repeats, enclosed in parentheses, and the number of repeats found in the source sequence in subscript. For example, (ct) is interpreted as "ctctctct". When the subscript number is indicated as, for example, n-1, this means the repeat was not perfect and either a base pair was missing or a base pair substitution was present in the repeat, compared with a perfect repeat sequence.

Table 2. These Fragaria (strawberry) and Rubus (raspberry and blackberry) genotypes were used to evaluate published and newly developed simple sequence repeat (SSR) primers in polymerase chain reactions (PCRs).

\begin{tabular}{|c|c|c|c|c|}
\hline $\begin{array}{l}\text { Accession } \\
\text { or plant } \\
\text { patent no }\end{array}$ & Plant species & $\begin{array}{l}\text { Cultivar or other } \\
\text { designator }\end{array}$ & $\begin{array}{l}\text { Location } \\
\text { tested }\end{array}$ & Comments \\
\hline PI 616505 & F. iinumae & CFRA 1008 & $\mathrm{C}$ & Another diploid species \\
\hline PI 551507 & F. vesca & 'Baron Solemacher' & $\mathrm{B}$ & $\begin{array}{l}\text { Diploid strawberry mapping } \\
\text { population }\end{array}$ \\
\hline None & F. vesca & WC6 & B & $\begin{array}{l}\text { Diploid strawberry mapping } \\
\text { population }\end{array}$ \\
\hline PI 9000 & F. vesca & UC5 & B & Diploid virus indicator \\
\hline PI 551646 & F. vesca subsp. bracteata & CFRA 389 & $\mathrm{C}$ & Diploid core accession, day-neutral \\
\hline PI 551908 & F. vesca subsp. vesca & ‘Snow King’ & $\mathrm{C}$ & White-fruited diploid strawberry \\
\hline PI 612490 & F. chiloensis & 'Scott's Creek' & $\mathrm{B}$ & Large-fruited, super core octoploid \\
\hline PI 612489 & F. chiloensis & HM 1 & B & $\begin{array}{l}\text { Highly productive, super core } \\
\text { octoploid }\end{array}$ \\
\hline PI 552038 & F. chiloensis & Island of Lemuy & $\mathrm{C}$ & White-fruited octoploid \\
\hline PI 551736 & F. chiloensis f. chiloensis & CFRA 372 & $\mathrm{C}$ & Super core octoploid \\
\hline $\begin{array}{l}\text { CFRA } \\
1806\end{array}$ & F. virginiana & US 4808 & B & $\begin{array}{l}\text { Octoploid resistant to Xanthomonas } \\
\text { fragariae }\end{array}$ \\
\hline $\begin{array}{l}\text { CFRA } \\
1807\end{array}$ & F. virginiana $\times(F$. $\times$ ananassa $)$ & US 4809 & B & $\begin{array}{l}\text { Octoploid resistant to Xanthomonas } \\
\text { fragariae }\end{array}$ \\
\hline PI 616561 & F. virginiana subsp. grayana & CFRA 1170 & $\mathrm{C}$ & Octop loid core accession \\
\hline PI 552250 & F. virginiana subsp. virginiana & WC 26 & $\mathrm{C}$ & Octop loid day-neutral \\
\hline PP 9,866 & F. $\times$ ananassa & 'Rosa Linda' & B & Florida-bred octoploid cultivar \\
\hline PP 5,266 & F. $\times$ ananassa & 'Selva' & B & $\begin{array}{l}\text { Day-neutral octoploid parent in } \\
\text { mapping population with } \\
\text { 'Delmarvel' }\end{array}$ \\
\hline PI 616589 & F. $\times$ ananassa & 'Delmarvel' & B & $\begin{array}{l}\text { Phytophthora Fragariae-resistant } \\
\text { octoploid parent in mapping } \\
\text { population with 'Selva' }\end{array}$ \\
\hline
\end{tabular}

Table 2 continued next page 
Table 2. Continued.

\begin{tabular}{|c|c|c|c|c|}
\hline $\begin{array}{l}\text { Accession } \\
\text { or plant } \\
\text { patent } \mathrm{no}^{\mathrm{z}} \\
\end{array}$ & Plant species & $\begin{array}{l}\text { Cultivar or other } \\
\text { designator }\end{array}$ & $\begin{array}{l}\text { Location } \\
\text { tested }^{\mathrm{y}}\end{array}$ & Comments \\
\hline None & F. $\times$ ananassa & 'Pelican' & B & $\begin{array}{l}\text { Colletotrichum species crown and } \\
\text { fruit rot-resistant octoploid parent in } \\
\text { mapping population with 'Chandler' }\end{array}$ \\
\hline PP 5,262 & F. $\times$ ananassa & 'Chandler' & B & $\begin{array}{l}\text { Widely adapted octoploid parent in } \\
\text { mapping population with 'Pelican' }\end{array}$ \\
\hline PP 8,729 & F. $\times$ ananassa & 'Sweet Charlie' & B & $\begin{array}{l}\text { Susceptible Florida-bred octoploid } \\
\text { parent cultivar in mapping } \\
\text { populations with US } 4808 \text { and US } \\
4809\end{array}$ \\
\hline PI 551394 & F. $\times$ ananassa & 'Earliglow' & $\mathrm{B}, \mathrm{C}$ & $\begin{array}{l}\text { Octoploid genotype from which a } \\
\text { genomic library for SSR } \\
\text { development was derived }\end{array}$ \\
\hline PI 551398 & F. $\times$ ananassa & 'Titan’ & $\mathrm{C}$ & Octoploid cultivar \\
\hline PI 551416 & F. $\times$ ananassa & 'Scott' & $\mathrm{C}$ & Red stele-resistant octoploid cultivar \\
\hline PI 551406 & F. $\times$ ananassa & 'Allstar' & $\mathrm{C}$ & $\begin{array}{l}\text { Widely adapted mid-Atlantic } \\
\text { octoploid cultivar }\end{array}$ \\
\hline PI 551490 & F. $\times$ ananassa & 'Hecker' & $\mathrm{C}$ & $\begin{array}{l}\text { First day-neutral octop loid cultivar } \\
\text { released in U.S. }\end{array}$ \\
\hline None & R. hybrid (blackberry) & APF12 & B & $\begin{array}{l}\text { Primocane-fruiting tetrap loid } \\
\text { blackberry in mapping population } \\
\text { with 'Arapaho' }\end{array}$ \\
\hline PP 8,510 & R. hybrid (blackberry) & 'Arapaho' & $\mathrm{B}$ & $\begin{array}{l}\text { Summer-fruiting tetrap loid } \\
\text { blackberry in mapping population } \\
\text { with APF } 12\end{array}$ \\
\hline PI 553276 & R. hybrid (blackberry) & 'Merton' & $\mathrm{B}$ & $\begin{array}{l}\text { Tetrap loid source of thornless trait in } \\
\text { U.S. blackberry genotypes }\end{array}$ \\
\hline PI 553348 & R. hybrid (blackberry) & 'Illini Hardy' & $\mathrm{B}$ & $\begin{array}{l}\text { Tetrap loid blackberry that produces } \\
\text { secondary floral initiation buds to } \\
\text { replace those damaged by cold }\end{array}$ \\
\hline None & R. idaeus (red raspberry) & NY322 & $\mathrm{B}$ & $\begin{array}{l}\text { Diploid red raspberry in mapping } \\
\text { population with 'Jewel' }\end{array}$ \\
\hline PI 553742 & R. occidentalis (black raspberry) & 'Jewel' & B & $\begin{array}{l}\text { Diploid black raspberry in mapping } \\
\text { population with NY322 }\end{array}$ \\
\hline
\end{tabular}

Table 3. Simple sequence repeat (SSR) primers derived from Fragaria (strawberry) and Rubus (bramble) sequences were tested in polymerase chain reactions (PCRs) with strawberry, blackberry, and raspberry genotypes. For each group of tested genotypes, the number of primers that were tested, the number that amplified a product, and the number that detected polymorphisms are reported.

\begin{tabular}{|c|c|c|c|c|c|c|c|c|c|c|c|}
\hline \multirow[b]{2}{*}{$\begin{array}{l}\text { SSR sequence } \\
\text { source }\end{array}$} & \multicolumn{5}{|c|}{ Strawberry } & \multicolumn{3}{|c|}{ Blackberry } & \multicolumn{3}{|c|}{ Raspberry } \\
\hline & $\begin{array}{l}\text { Number } \\
\text { tested }\end{array}$ & $\begin{array}{l}\text { Number } \\
\text { amplified }\end{array}$ & $\begin{array}{l}\text { Number } \\
\text { polymorphic }\end{array}$ & $\begin{array}{l}\text { Polymorphic } \\
\text { in octoploid } \\
\text { parents }^{z}\end{array}$ & $\begin{array}{l}\text { Poly morphic } \\
\text { in diploid } \\
\text { parents }\end{array}$ & $\begin{array}{l}\text { Number } \\
\text { tested }\end{array}$ & $\begin{array}{l}\text { Number } \\
\text { amplified }\end{array}$ & $\begin{array}{l}\text { Polymorphic } \\
\text { in tetrap loid } \\
\text { parents }^{\mathrm{x}}\end{array}$ & $\begin{array}{l}\text { Number } \\
\text { tested }\end{array}$ & $\begin{array}{l}\text { Number } \\
\text { amplified }\end{array}$ & $\begin{array}{l}\text { Polymorphic } \\
\text { in diploid } \\
\text { parents }^{\mathrm{W}}\end{array}$ \\
\hline$\overline{\text { Fragaria genomic }}$ & 28 & 24 & 24 & $19 / 24$ & $9 / 18$ & 23 & 6 & $3 / 6$ & 28 & 5 & $3 / 5$ \\
\hline Fragaria GenBank & 34 & 26 & 15 & $10 / 17$ & - & 19 & 6 & $1 / 5$ & 20 & 4 & $1 / 4$ \\
\hline$F$. vesca & 10 & 10 & 8 & $7 / 10$ & - & 8 & 1 & $0 / 1$ & 10 & 2 & $2 / 2$ \\
\hline F. virginiana & 4 & 4 & 4 & $1 / 1$ & - & 1 & 1 & $0 / 1$ & 4 & 1 & $0 / 1$ \\
\hline Rubus alceifolius & 8 & 0 & - & - & - & 8 & 2 & $1 / 2$ & 8 & 2 & $2 / 2$ \\
\hline
\end{tabular}

zThe octoploid strawberry mapping parents are US 4808 and 'Sweet Charlie'.

yThe diploid strawberry mapping parents are 'Baron Solemacher' and WC6.

xThe tetraploid blackberry mapping parents are 'Arapaho' and Univ. of Arkansas selection APF-12.

wThe diploid raspberry mapping parents are Cornell Univ. red raspberry selection NY322 and black raspberry cultivar Jewel. 
for a primer pair was initially determined by gradient PCR using template DNA from two cultivars of $F$. ×ananassa 'Rainier' and 'Earliglow' at $55^{\circ} \mathrm{C} \pm 10^{\circ} \mathrm{C}$.

At Beltsville, PCR components included $1 \times$ Qiagen PCR buffer (1.5 mM $\mathrm{MgCl}_{2}$ ), $0.67 \mathrm{~mm}$ dNTPs (higher than usual to facilitate amplification through repeat regions), $0.5 \mu \mathrm{M}$ each primer, and 0.4 U HotStar Taq polymerase enzyme, and template DNA at either 2 $\mathrm{ng} \cdot \mu \mathrm{L}^{-1}$ (standard stringency) or $0.002 \mathrm{ng} \cdot \mu \mathrm{L}^{-1}$ (high stringency) in a total reaction volume of $15 \mu \mathrm{L}$. Reaction components were heated to $95^{\circ} \mathrm{C}$ for $15 \mathrm{~min}$ to activate the polymerase. The heatactivation period was followed by 30 cycles of $40 \mathrm{~s}$ at $95^{\circ} \mathrm{C}, 40$ $\mathrm{S}$ at $52{ }^{\circ} \mathrm{C}$ (for primers designed from the genomic library) or 59 ${ }^{\circ} \mathrm{C}$ (for primers designed from GenBank sequences), and $40 \mathrm{~s}$ at $72{ }^{\circ} \mathrm{C}$, followed by $10 \mathrm{~min}$ at $72{ }^{\circ} \mathrm{C}$ and storage at $4{ }^{\circ} \mathrm{C}$. The thermal cycler was the MJ Research Engine Tetrad with 96-well blocks. For some reactions a PCR gradient was used from $52{ }^{\circ} \mathrm{C}$ through $62{ }^{\circ} \mathrm{C}$ using the gradient option.

PCR FRAGMENTANALYSIS. At Corvallis, PCR products and a 100bp-size standard (Promega, Madison Wis.) were separated on 3\% GenePure LE agarose (ISC BioExpress, Kaysville, Utah) at $100 \mathrm{~V}$ for $180 \mathrm{~min}$. The DNA fragments were visualized after ethidium bromide staining using the GelDoc 2000 gel documentation system (BioRad, Hercules, Calif.). To detect polymorphisms, fragment sizes were estimated by Quantity One software (BioRad).

To determine if the reactions resulted in a product, at Beltsville, PCR products were diluted in water and visualized after 12 min of electrophoresis through a $2 \%$ agarose gel using Invitrogen's E-gel 96 system. Gel images were captured in .tif files using the AlphaImager (Alpha Innotech Corp., San Leandro, Calif.), analyzed with the E-gel 96 Editor software (Alpha Innotech Corp.).

To size the PCR products and identify polymorphisms at Beltsville, florescently labeled primers were ordered from Applied Biosystems and PCR was repeated. Fluorescently labeled PCR products were separated by capillary gel electrophoresis and detected using the Applied Biosystems, 3700 DNA Analyzer. The size standard used was GENESCAN 400HD [ROX]. Sizing data were analyzed using ABIs Genotyper (Applied Biosystems) software.

\section{Results}

DETERMINING FUnCTIONAL TAXONOMIC DISTANCE FOR SSR DEVELOPMENT. GenBank sequences containing $(\mathrm{CT})_{\mathrm{n}}$ repeats were obtained from $F$. ×ananassa, Rosa, Prunus persica, Malus $\times d o$ mestica, Pyrus communis, Medicago truncatula, Glycine max, Gossypium, and Arabidopsis thaliana, and primers designed from six of each species were initially tested to see if they would amplify products from Fragaria, Rubus, P. persica, or G. max template DNA in PCR amplifications. None of the P. persica, $M$. $\times$ domestica, P. communis, M. truncatula, G. max, Gossypium, or A. thaliana primers amplified products from Fragaria or Rubus DNA. Of the previously published SSRs tested, the 21 primer pairs designed from $P$. persica genomic sequences and reported by Dirlewanger et al. (2002) to amplify products from Fragaria genomic DNA, successfully amplified a product from $P$. persica DNA but failed in our attempts with varying PCR conditions to amplify products from Fragaria or Rubus DNA. In addition, only Prunus-derived primers amplified products from $P$. persica DNA, and only G. max-derived primers amplified a product from G. max DNA. Therefore, transference of SSRs from distantly related genera was less successful than expected based on previous reports.
Transference of SSRs among Rosoideae genera was tested using previously published SSRs from Fragaria and Rubus species, including four primer pairs designed from $F$. virginiana genomic sequences (Ashley et al., 2003), 10 SSRs designed from genomic sequences of $F$. vesca (diploid strawberry) by James et al. (2003), and eight primer pairs developed from $R$. alceifolius (Amsellem et al., 2001), as well as six new GenBank-derived $F$. ×ananassa primers. One of the four primer pairs designed from $F$. virginiana genomic sequences (Ashley et al., 2003) amplified both blackberry and raspberry DNA. Three of the 10 SSRs designed from $F$. vesca (diploid strawberry) genomic sequences by James et al. (2003) amplified products from blackberry, and two of those amplified products from raspberry. One of the six $F$. xananassa primers amplified a product from blackberry, and one amplified a product from raspberry. In total, $27 \%$ and $19 \%$ of these Fragaria-derived primer pairs amplified a product in blackberry and/or raspberry, respectively. Interestingly, of the eight primer pairs developed from $R$. alceifolius (Amsellem et al., 2001), only two amplified a product from blackberry and raspberry, so that using the $R$. alceifolius-derived SSRs with blackberry and raspberry was no better than using the Fragaria-derived SSRs. None of the eight $R$. alceifolius-derived primer pairs amplified a product from Fragaria DNA. In addition, none of the Rosa-derived primers amplified a product from Fragaria or Rubus. To confirm this finding, 24 additional Rosa-derived SSR primer pairs (data not shown) were tested with Fragaria and Rubus DNA, and, again, none amplified a product. Therefore, some SSRs were transferable between some Rosoideae genera, but not others.

Transference of SSRs between Fragaria congeners was highly successful. The published $F$. virginiana and $F$. vesca SSRs (Ashley et al., 2003; James et al., 2003) were used in addition to six GenBank $F$. xananassa-derived primers to test for intrageneric amplification. These 20 primer pairs amplified products from all the Fragaria templates tested, including $F$. ×ananassa, $F$. virginiana, $F$. chiloensis, and $F$. vesca (Tables 1 and 3 ). These results support the conclusion made by Ashley et al. (2003) and Sargent et al. (2003) that primers designed from one Fragaria species generally can be used with other Fragaria species.

GENBANK-DERIVED SSRS AND CROSS-SPECIFIC AMPLIFICATION AND POLYMORPHISM IN FRAGARIA. Because transference of SSRs between Fragaria congeners was so successful, we developed new strawberry SSRs using Fragaria sequences archived in GenBank.

Of the two methods used to identify SSR-containing Fragaria sequences from GenBank, SSRIT was superior to BLAST in that it detected a larger number of repeats as well as a greater diversity of repeat motifs. From the 306 Fragaria sequences in GenBank, SSRIT identified 42 with a minimum of five tandem repeats and 227 sequences with a minimum of 4 tandem repeats. The motifs uniquely identified by SSRIT included AAAAT (FAC001), CTT (Fac0010, FAC-010), AAG (FAC-003, FAC-013), and GCT (FAC-016). BLAST identified 57 Fragaria sequences containing repeats.

All primer pairs designed from GenBank sequences using both methods amplified a product in the source species $F$. xananassa except for FAC-010. SSRs FAC-012 and FAC-014, designed from $F$. vesca, amplified PCR fragments of the expected size in $F$. chiloensis, $F$. virginiana, and $F$. xananassa. It is of interest to note that FAC-012 failed to amplify in the source species, $F$. vesca. The amplification rate using GenBank-derived SSR primers was high within the Fragaria genus (73\% in $F$. vesca; $79 \%$ in $F$. iinumae; $88 \%$ in the octoploid $F$. chiloensis and $F$. virginiana; 
and $92 \%$ in the source species $F$. ×ananassa). Likelihood of polymorphism detection seemed to increase as the number of simple sequence repeats increased, though we were not able to determine if the apparent increase was statistically significant. Of GenBank-derived SSR primers that amplified a product, $68 \%$ with six or more repeats detected polymorphisms among tested accessions, and $43 \%$ with fewer than six repeats detected polymorphisms. Between the octoploid strawberry parents (US 4808 $\times$ 'Sweet Charlie') of a genetic mapping population, $59 \%$ of the GenBank-derived primers detected polymorphisms.

EFFECT OF REPEAT LOCATION ON AMPLIFICATION AND POLYMORPHisM DETECTION. Simple sequence repeats were found in all regions of genes: ten were present in $5^{\prime}$ UTRs, eight in $3^{\prime}$ UTRs, eleven in coding regions and three were detected in introns (Table 1). The SSRs identified from the 5'UTRs contained mostly dinucleotide repeats (7 out of 10) and $80 \%$ detected polymorphisms among the $F$. $\times$ ananassa accessions tested. All five of the dinucleotide-containing SSRs isolated from 3'UTRs detected polymorphisms among $F$. ×ananassa, while only one out of the three trinucleotide-containing SSRs detected polymorphisms. Trinucleotide repeats were the most abundant type found in the coding regions as previously reported in other plant species (Smulders et al., 1997). Seven of the eleven SSRs identified in exons contained trinucleotide repeats. Three of these trinucleotidecontaining SSRs (42\%) identified in Fragaria coding sequences detected polymorphisms. The number of SSRs detected in introns was small in this study. Out of 3 intron-located SSRs, only one, FAC-008, detected polymorphisms within $F$. vesca, F. chiloensis, $F$. virginiana and $F$. xananassa. In spite of these trends, ARSFL_33, derived from a Fragaria sequence and having only four tandem repeats in a coding region detected polymorphisms between raspberry genotypes.

SSRS DEVELOPED FROM A F RAGARIA GENOMIC LIBRARY. Both the amplification success rate and the percentage of polymorphism detected by SSRs derived from the genomic library were $85 \%$. Seventy-seven percent of SSRs derived from the genomic library, averaged across $F$. xananassa, $F$. vesca, and $F$. virginiana, detected polymorphisms. Of the SSRs derived from the $F$. xananassa genomic library, 79\% detected polymorphisms between parents of an octoploid population (US4840 × 'Sweet Charlie') and 50\% between the parents of a diploid population ('Baron Solemacher' $\times$ WC6) (Davis and Yu, 1997). The SSR primers derived from the genomic library detected more polymorphisms than those derived from GenBank sequences (Table 3).

GENOMIC- AS OPPOSED TO GENB ANK-DERIVED SSRS IN F RAGARIA. There were no noticeable differences in ability to amplify a product that could be associated with SSR derivation from the genomic library or GenBank sequences. Among SSRs derived from the genomic library, all but ARSFL_18 and ARSFL_20 amplified a product from at least one genotype, and among GenBank-derived SSRs, all but FAC-010, ARSFL_105, and ARSFL_107 amplified a product. ARSFL_19, derived from the genomic library, amplified a product from some genotypes but not its source genome $F$. xananassa. Similarly, GenBank-derived SSRs FAC-006b and FAC-012 did not amplify a product from their respective source genomes, $F$. xananassa and $F$. vesca, though they did amplify products from other genomes. However, SSRs developed from the genomic library rather than GenBank sequences detected more polymorphisms (Table 3).

Cross-SPECIES AMPlifiCATION AND POLYMORPHISM OF SSRS WITHIN FRAGARIA. Within Fragaria, there were no significant differences in SSR ability to amplify a product associated with
SSR source species (Tables 1 and 3). SSRs developed from $F$. $\times$ ananassa, $F$. virginiana, and $F$. vesca seemed equally capable of amplifying products from any Fragaria species and detecting polymorphisms between genotypes within species. Twenty-one of the twenty-two primer pairs obtained from $F$. xananassa were cross-transferable to the progenitor octoploids, $F$. chiloensis and $F$. virginiana. In the diploid species, $F$. iinumae and $F$. vesca, 19 and 17 of the $22 F$. xananassa primers, respectively, amplified the expected size fragments. Furthermore, $66 \%$ of the $F$. xananassa-derived SSRs detected polymorphisms between parents of the octoploid strawberry genetic mapping population(US $4808 \times$ 'Sweet Charlie') and $56 \%$ between parents of the diploid strawberry population ('Baron Solemacher' $\times$ WC6).

Cross-generic AMPLIFICATION AND POLYMORPHISM OF SSRs BETWEEN F RAGARIA AND RUbUS. Because some SSRs were transferable between some Rosoideae genera, but not others, cross-generic amplification between Fragaria and Rubus was evaluated further using new Fragaria BLAST-identified SSRs as well as $22 \mathrm{~F}$. $\times$ ananassa genomic SSR primer pairs. Between $26 \%$ to $31 \%$ of the new Fragaria genomic and GenBank-derived primer pairs resulted in amplification of product from blackberry and $17 \%$ to $20 \%$ from raspberry (Table 3 ). In total, ten Fragaria-derived SSR primers amplified products from both blackberry and raspberry, although only two detected polymorphisms. Five SSR primers amplified products from only blackberry (three detected polymorphisms), and three SSR primers amplified products from only raspberry (two detected polymorphisms). Of SSR primers that amplified a product, the percentage that detected polymorphisms ranged from $20 \%$ to $60 \%$ with $35 \%$ average for blackberry, and $43 \%$ average for raspberry.

\section{Discussion}

Transference of SSRs among distantly related genera was unsuccessful as sequences derived from other genera did not amplify a product from the Fragaria and Rubus genotypes we tested. Although rose is in the same subfamily, Rosoideae, the thirty primer pairs we designed from rose sequences did not amplify a product from any strawberry or bramble genotype. And, although SSRs derived from peach have been reported to amplify a product from strawberry, the 21 peach-derived SSRs reported by Dirlewanger et al. (2002) to amplify products from strawberry failed in our attempts with varying PCR conditions to amplify products from Fragaria or Rubus DNA. However, these and six primers we designed from peach sequences in GenBank amplified a product from peach DNA. This is especially significant, because peach recently has been proposed as a model species for the entire Rosaceae family. Our findings indicate that peach SSRs will not be as useful as initially hoped for Fragaria and Rubus species and support the findings of Peakall et al. (1998) and Decroocq et al. (2003) on limited cross-species transferability in the Rosaceae family. Decroocq and co-workers (2003) found that optimal utility of Prunus armeniaca L. (apricot) EST SSR markers was obtained for closely related species belonging to the same subgenus Prunophora, and that the threshold distance after which no amplification can be expected is short in the Rosaceae family. It is likely that a small percentage of primers designed from Prunus and other Rosaceae genera will reliably amplify a product from strawberry, raspberry, or blackberry, and these primers eventually will be very valuable for genome comparison. However, the percentage appears to be too small to be practical in quickly developing SSRs and maps for marker-assisted selection. 
Therefore, genome comparisons among species from different Rosaceae subfamilies might be more efficient with hybridization techniques than with PCR-based techniques.

Sequences from any Fragaria species appear to be equally useful for designing SSRs for any other Fragaria species. Current research projects developing EST sequences from $F$. vesca as a model for studying gene expression in strawberry should yield many repeat-containing sequences from which SSRs can be designed and used with any of the Fragaria species. Other research projects developing ESTs from $F$. xananassa, likewise, should yield widely useful SSRs. The SSRs we tested have limited transference between Fragaria and Rubus, and these SSRs are particularly interesting for comparative mapping. For example, SSRs associated with resistance to a pathogen in strawberry may be associated with resistance to a similar pathogen in raspberry and blackberry.

Although $30 \%$ to $50 \%$ of strawberry-derived SSRs amplified a product in raspberry and blackberry, only about $30 \%$ to $50 \%$ of these detected a polymorphism between parents of the raspberry ('Jewel' $\times$ NY322) or blackberry (APF-12 × 'Arapaho') mapping populations we tested. Therefore, only about $10 \%$ of the strawberry-derived SSRs were useful in mapping in these two populations. It seems clear that dependence on strawberryderived SSRs is insufficient for genetic mapping in Rubus, and Rubus sequences are required.

Transference among Rubus species was not as successful as among Fragaria species. SSRs from the Asian (Indonesia and south east China) native noxious weed $R$. alceifolius, a member of the subgenus Malachobatus, exhibited only limited crossspecies transference to raspberry (subgenus Idaeobatus) or to blackberry (subgenus Rubus, formerly Eubatus). Rubus is one of the most diverse genera in the plant kingdom and considerable differentiation of species exists in the three subgenera used in this study (Jennings, 1988). It may be necessary to develop raspberry SSRs for use with raspberry and blackberry SSRs for use with blackberry.

Both BLAST and SSRIT can be used to screen in-house library sequences for SSRs without first having to deposit sequences in GenBank. Other SSR identification tools include two designed to work with the Linux operating system: TROLL (Castelo et al., 2002; Source Forge, 2001); and Sputnik available at (Espresso Software Development, 2003). A fourth tool, MISA, present at [Institute of Plant Genetics and Crop Plant Research (IPK) Plant Genome Resources Center, 2002; Thiel et al., 2003] is designed to interface with the Primer3 primer design software with the help of two PERL scripts available on the web site. We compared BLAST and SSRIT and found SSRIT was superior to BLAST, because it identified more GenBank sequences containing repeats and detected a greater diversity of repeat motifs.

SSR primers developed from the genomic library seemed better able to detect polymorphisms among accessions and between parents of mapping populations (Table 3). It is possible that the SSRs derived from the genomic library were more likely to detect polymorphisms because of the larger repeat regions found in the genomic library sequences (Table 1). Among SSRs derived from GenBank accessions, the ability to detect polymorphisms among accessions increased from $43 \%$ to $68 \%$ as the number of repeats increased from fewer than six repeats to six or more repeats. This suggests SSRs derived from GenBank sequences with six or more repeats would be as likely to detect polymorphisms as would SSRs derived from a genomic library. If a genomic library is not already available, development of SSRs from GenBank sequences may be more efficient than from a genomic or cDNA library. On the other hand, if the number of sequences deposited in GenBank is insufficient for genetic mapping, development and sequencing of a library is warranted. Since Morgante et al. (2002) showed that SSRs are associated with gene clusters in plants, SSRs developed from cDNA sequences or genomic sequences may be equally likely to be associated with traits. The choice of whether to make a cDNA library or genomic library for SSR development could depend on several factors, including: additional research interests that could be better addressed with one library compared to the other; relative cost of making the two different library types; and technical skills of and services available to the researchers involved.

\section{Literature Cited}

Akkaya, M.S., R. Shoemaker, J.E. Specht, A.A. Bhagwat, and P.B. Cregan. 1995. Integration of simple sequence repeat (SSR) DNA markers into a soybean linkage map. Crop Sci. 35:1439-1445.

Aldrich, P.R. and J.L. Hamrick. 1998. Reproductive dominance of pasture trees in a fragmented tropical forest mosaic. Science 281:103-105.

Altschul, S.F., W. Gish, W. Miller, E.W. Myers, and D.J. Lipman. 1990. Basic local alignment search tool. J. Mol. Biol. 215:403-410.

Amsellem, L., C. Dutech, and N. Billotte. 2001. Isolation and charaterization of polymorphic microsatellite loci in Rubus alceifolius Poir (Rosaceae), an invasive weed in La Réunion island. Mol. Ecol. Notes 1:33-35.

Ashley, M.V., J.A. Wilk, S.M.N. Styan, K.J. Craft, K.L. Jones, K.A. Feldheim, K.S. Lewers, and T.L. Ashman. 2003. High variability and disomic segregation of microsatellites in the octoploid Fragaria virginiana Mill (Rosaceae). Theor. Appl. Genet. 107:1201-1207.

Broun, P. and S.D. Tanksley. 1996. Characterization and genetic mapping of simple repeat sequences in the tomato genome. Mol. Gen. Genet. 250:39-49.

Castelo,A.T., W. Martins, and G.R. Gao. 2002. TROLL_-Tandem repeat occurrence locator. Bioinformatics 18:634-636.

Chase, M.R., C. Moller, R. Kesseli, and K.S. Bawa. 1996. Distant gene flow in tropical trees. Nature 383:398-399.

Cho, Y.G., T. Ishii, S. Temnykh, X. Chen, L. Lipovich, S.R. McCouch, W.D. Park, N. Ayres, and S. Cartinhour. 2000. Diversity of microsatellites derived from genomic libraries and GenBank sequences in rice (Oryza sativa L.). Theor. Appl. Genet. 100:713-722.

Cipriani, G., G. Lot, W.-G. Huang, M.T. Marrazzo, E. Peterlunger, and R. Testolin 1999. AC/GT and AG/CT microsatellite repeats in peach [Prunus persica (L) Batsch]: Isolation, characterization and cross-species amplification in Prunus. Theor. Appl. Genet. 99:65-72.

Cordeiro, G.M., R. Casu, C.L. McIntyre, J.M. Manners, and R.J. Henry. 2001. Microsatellite markers from sugarcane (Saccharum spp) ESTs cross transferable to erianthus and sorghum. Plant Sci. 160:1115-1123.

Cregan, P.B., T. Jarvik, A.L. Bush, R.C. Shoemaker, K.G. Lark, A.L. Kahler, N. Kaya, T.T. VanToai, D.G. Lohnes, J. Chung, and J.E. Specht. 1999. An integrated genetic map of the soybean genome. Crop Sci. 39:1464-1490.

da Silva, J.A.G. 2001. Preliminary analysis of microsatellite markers derived from sugarcane expressed sequence tags (ESTs). Genet. Mol. Biol. 24:155-159.

Davis, T.M. and H. Yu. 1997. A linkage map of the diploid strawberry Fragaria vesca. J. Hered. 88:215-221.

Dayanandan, S., K.S. Bawa, and R. Kesseli. 1997. Conservation of microsatellites among tropical trees (Leguminosae). Amer. J. Bot. 84:1658-1663.

Decroocq, V., M.G. Favé, L. Hagen, L. Bordenave, and S. Decroocq. 2003. Development and transferability of apricot and grape EST microsatellite markers across taxa. Theor. Appl. Genet. 106:912-922.

Dirlewanger, E., P. Cosson, M. Tavaud, M. Aranza, C. Poizat, A. Zanetto, P. Arús, and F. Laigret. 2002. Development of microsatellite markers in peach [Prunus persica (L) Batsch] and their use in genetic diversity 
analysis on peach and sweet cherry (Prunus avium L). Theor. Appl. Genet. 105:127-138.

Downey, S.L. and A.F. Iezzoni. 2000. Polymorphic DNAmarkers in black cherry (Prunus serotina) are identified using sequences from sweet cherry, peach, and sour cherry. J. Amer. Soc. Hort. Sci. 125:76-80.

Echt, C.S., G.G. Vendramin, C.D. Nelson, and P. Marquardt. 1999. Microsatellite DNA as shared genetic markers among conifer species. Can. J. For. Res. 29:365-371.

Espresso Software Development. 2003. Sputnik. 6 June 2004. <http:// espressosoftware.com/pages/sputnik.jsp>.

Fazio G., S.M. Chung, and J.E. Staub. 2003. Comparative analysis of response to phenotypic and marker-assisted selection for multiple lateral branching in cucumber (Cucumis sativis L.). Theo. Appl. Genet. 107:875-883.

Graham, J., K. Smith, M. Woodhead, and J. Russell. 2002. Development and use of simple sequence repeat SSR markers in Rubus species. Mol. Ecol. Notes 2:250-252.

Gramene. 2004. SSRIT-Simple sequence repeat identification tool. 6 June 2004. <http://www.gramene.org/db/searches/ssrtool>

Holland, J.B., S.J. Helland, N. Sharopova, and D.C. Rhyne. 2001. Polymorphism of PCR-based markers targeting exons, introns, promoter regions, and SSRs in maize and introns and repeat sequences in oat. Genome 44:1065-1076.

Institute for Chemical Research. 2000. Clustal W multiple sequence alignment. 6 June 2004. <http://clustalw.genome.jp/>.

Institute of Plant Genetics and Crop Plant Research (IPK) Plant Genome Resources Center. 2002. MISA-MIcroSAtellite identification tool. 6 June 2004. <http://pgrc.ipk-gatersleben.de/misa/>.

Isagi, Y. and S. Suhandono. 1997. PCR primers amplifying microsatellite loci of Quercus myrsinifolia Blume and their conservation between oak species. Mol. Ecol. 6:897-899.

James, C.M., F. Wilson, A.M. Hadonou, and K.R. Tobutt. 2003. Isolation and characterization of polyploid microsatellites in diploid strawberry (Fragaria vesca L.) for mapping, diversity studies and clone identification. Mol. Ecol. Notes 3:171-173.

Jennings, D.L.. 1988. Raspberries and blackberries: Their breeding, diseases and growth. Academic, San Diego.

Kantety, R.V., M. La Rota, D.E. Matthews, and M.E. Sorrells. 2002. Data mining for simple sequence repeats in expressed sequence tags from barley, maize, rice, sorghum and wheat. Plant Mol. Biol. 48:501-510

Morgante, M., M. Hanafey, and W. Powell. 2002. Microsatellites are preferentially associated with nonrepetitive DNA in plant genomes. Nature Genet. 194-200.

National Center for Biotechnology Information. 2004. BLAST. 6 June 2004. <http://www.ncbi.nlm.nih.gov/BLAST/>.

Peakall, R., S. Gilmore, W. Keys, M. Morgante, and A. Rafalski. 1998. Cross-species amplification of soybean (Glycine max) simple sequence repeats (SSRs) within the genus and other legume genera: Implications for the transferability of SSRs in plants. Mol. Biol. Evol. 15:1275-1287.

Rajora, O.P., M.H. Rahman, S. Dayanandan, and A. Mosseler. 2001. Isolation, characterization, inheritance and linkage of microsatellite DNA markers in white spruce (Picea glauca) and their usefulness in other spruce species. Mol. Gen. Genet. 264:871-882.

Rongwen, J., M.S. Akkaya, A.A. Bhagwat, U. Lavi, and P.B. Cregan. 1995. The use of microsatellite DNA markers for soybean genotypes identification. Theor. Appl. Genet. 90:43-48.

Rozen, S. and H.J. Skaletsky. 2000. Primer3 on the WWW for general users and for biologist programmers, p. 365-386. In: S. Krawetz, and S. Misener (eds.). Bioinformatics methods and protocols: Methods in molecular biology. Humana Press, Totowa, N.J.

Sargent, D.J.,A.M.Hadonou, and D.W. Simpson. 2003. Development and characterization of polymorphic microsatellite markers from Fragaria viridis, a wild diploid strawberry. Mol. Ecol. Notes 3:550-552.

Scott, K.D., P. Eggler, G. Seaton, M. Rossetto, E.M. Ablett, L.S. Lee, and R.J. Henry. 2000. Analysis of SSRs derived from grape ESTs. Theor. Appl. Genet. 100:723-726.

Smulders, M.J.M., G. Bredeijer, W. Rus-Kortekaas, P. Arens, and B. Vosman. 1997. Use of short microsatellites from database sequences to generate polymorphisms among Lycopersicon esculentum cultivars and accessions of other Lycopersicon species. Theor. Appl. Genet. 97:264-272.

Source Forge. 2001. TROLL_-Tandem repeat occurrence locator. 6 June 2004. <http://finder.sourceforge.net>

Steinkellner, H., C. Lexer, E. Turetschek, and J. Glossl. 1997. Conservation of $(\mathrm{GA})_{\mathrm{n}}$ microsatellite loci between Quercus species. Mol. Ecol. 6:1189-1194.

Temnykh, S., G. DeClerck, A. Lukashova, L. Lipovich, S. Cartinhour, and S. McCouch. 2001. Computational and experimental analysis of microsatellites in rice (Oryza sativa L.): Frequency, length variation, transposon associations, and genetic marker potential. Genome Res. 11:1441-1452.

Thiel, T., W. Michalek, R.K. Varshney, and A. Graner. 2003. Exploiting EST databases for the development and characterization of genederived SSR-markers in barley (Hordeum vulgare L.). Theor. Appl. Genet. 106:411-422.

Thompson, J.D., D.G. Higgins, and T.J. Gibson. 1994. CLUSTAL W: Improving the sensitivity of progressive multiple sequence alignment through sequence weighting, positions-specific gap penalties and weight matrix choice. Nucleic Acids Res. 22:4673-4680.

Whitehead Institute for Biomedical Research. 2004. Primer3. 6 June 2004.

Whitton, J., L.H. Rieseberg, and M.C. Ungerer. 1997. Microsatellite loci are not conserved across the Asteraceae. Mol. Biol. Evol. 14:204-209. 